\title{
Productivity in Small Business: An Analysis Using African Data
}

\section{A. Roy Thurik}

Labor and floorspace cost functions are derived for small business trade. Relationships are proposed between average volume of labor or average floorspace per establishment on the one hand, and average size per establishment, average rental paid, percentage selling space, and indicators of business type and location on the other. Promising estimation results are reported using South African data of $1979 / 1980$. The method however is not restricted to the South African case. A productivity business support system can be developed providing productivity standards for any area in the small (service) business. An analysis similar to the one presented here, but relating to the area in question, should precede the development of such a system.

This paper deals with the investigation of differences in average labor and floorspace productivity among small business trade groups in the Pretoria area (Republic of South Africa). A trade group or establishment type is defined as a group of establishments which offer essentially the same product mix and service level. The trade groups include retail establishments, catering businesses and handicrafts. Among trade groups there are considerable differences in average size per establishment, price of labor, rental paid, type of product etc. Differences in average labor and floorspace productivity per trade group are explained using some of the properties mentioned above to study the role of the location and investigate whether labor and floorspace productivity can be studied separately. Special attention is paid to the consequences of a central location as opposed to a suburban or isolated one.

The relationship used to conduct this study is an aggregate form of a relationship which has been successfully used to explain differences in labor and floorspace productivity per shop in the retail trade. The relationships used in this paper are promising, because their specification is plausible in the light of recently developed theories on the level of individual shops. Interesting conclusions can be drawn (regarding economies of scale, rental paid, location etc.), and interesting applications can be envisioned.

Estimations reported here refer to data of 1979/1980 from 23 trade groups partitioned into 96 subgroups involving 1,128 establishments. Generally, average labor volume per establishment does not exceed ten persons across the trade groups. This paper will not be burdened with a precise definition of all the trade groups involved. An impression of their average size in terms of labor volume, total floorspace and annual sales is given in Table 1. On the whole the establish- 
Data Used for the Analysis (1979/1980 Data)

\begin{tabular}{|c|c|c|c|c|c|c|}
\hline Trade Group & $\begin{array}{c}\text { Table } \\
\text { Number }\end{array}$ & $\begin{array}{c}\text { Number } \\
\text { of } \\
\text { Subgroups }\end{array}$ & $\begin{array}{c}\text { Total } \\
\text { Number of } \\
\text { Establishments }\end{array}$ & $\begin{array}{c}\text { Average } \\
\text { Volume } \\
\text { of Labor } \\
\text { (L) }\end{array}$ & $\begin{array}{c}\text { Average } \\
\text { Total } \\
\text { Floorspace } \\
(\mathbf{F})\end{array}$ & $\begin{array}{c}\text { Average } \\
\text { Sales } \\
\text { Value } \\
\text { (Q) }\end{array}$ \\
\hline Chemists & 7. 1.2 & 6 & 96 & 6.8 & 155 & 26.1 \\
\hline General dealers & 7. 2. 2 & 5 & 39 & 2.9 & 142 & 8.1 \\
\hline Florists & 7. 3. 2 & 4 & 32 & 3.7 & 82 & 5.1 \\
\hline Gifts and crockery & 7. 4.2 & 2 & 14 & 3.4 & 143 & 7.8 \\
\hline Restaurants & 7. 5.2 & 5 & 61 & 13.6 & 224 & 15.9 \\
\hline Take-away foods & 7. 5.6 & 3 & 19 & 7.0 & 134 & 12.1 \\
\hline Jewelers & 7. 6.2 & 4 & 46 & 3.9 & 86 & 17.0 \\
\hline Book-shops & 7. 7.2 & 4 & 29 & 5.9 & 269 & 24.4 \\
\hline Liquor trade & 7. 9.2 & 5 & 53 & 7.8 & 272 & 59.3 \\
\hline Drycleaners & 7.10. 2 & 4 & 27 & 5.9 & 123 & 3.4 \\
\hline Repair services & 7.10. 6 & 2 & 8 & 8.7 & 199 & 11.7 \\
\hline Shoes and & & & & & & \\
\hline leather goods & 7.11. 2 & 4 & 64 & 5.0 & 185 & 15.8 \\
\hline Butchers & 7.13. 2 & 6 & 62 & 7.9 & 155 & 29.1 \\
\hline Cafés & 7.14. 2 & 5 & 78 & 4.9 & 185 & 12.6 \\
\hline Greengrocers & 7.14. 6 & 3 & 21 & 3.0 & 84 & 6.7 \\
\hline Men's clothing & 7.16. 2 & 4 & 67 & 5.1 & 181 & 19.2 \\
\hline Ladies clothing & 7.16. 6 & 5 & 67 & 8.3 & 197 & 22.6 \\
\hline General clothing & 7.16 .10 & 5 & 80 & 7.9 & 282 & 25.4 \\
\hline Supermarkets & 7.17. 2 & 4 & 20 & 7.9 & 394 & 30.1 \\
\hline Furniture and & & & & & & \\
\hline electrical appliances & 7.18. 2 & 5 & 132 & 11.5 & 704 & 46.4 \\
\hline Hardware & 7.19. 2 & 5 & 46 & 7.8 & 334 & 29.8 \\
\hline $\begin{array}{l}\text { Carpets, curtains } \\
\text { and material }\end{array}$ & 7.20. 2 & 4 & 43 & 5.5 & 167 & 16.6 \\
\hline $\begin{array}{l}\text { Butchers in } \\
\text { chain stores }\end{array}$ & 7.23. 2 & $\frac{2}{96}+$ & $\frac{24}{1,128}+$ & 7.9 & 69 & 38.5 \\
\hline
\end{tabular}

Notes: $\mathrm{L}$ is expressed in persons engaged, $\mathrm{F}$ in square metres and $\mathrm{Q}$ in ten thousand South African rands (1 S. Afr. rand $\simeq 1.2 \mathrm{Am}$. Dollar in 1980). Table number refers to "Sales, rental, and establishment size and their interrelationships in the municipal area of Pretoria 1979/1980," Report No. A \& C Bureau of Financial Analysis, University of Pretoria, 1981.

ments involved should be associated with rural European or North American trade types.

It is not the aim of this paper to provide assistance to the European or North American small business community in the sense that the paper gives unambiguous hints to improve productivity. The paper provides a method which should be replicated for certain countries, regions or trade groups in order to support specific productivity consultancy questions. The Research Institute for Small and Medium Sized Business in the Netherlands is developing an automated business support system whose method is very close to and derived from the one discussed in this paper. Since the paper aims at a methodological contribution the data used 
need not be recent. The best data available happened to be South African. Earlier exercises using French and Dutch retail data showed results comparable to those presented here. This fact supports the general applicability of the method used.

Throughout this paper many references will be made to the work (mainly European) of Nooteboom and Thurik on retail cost functions. These references will provide a thorough presentation of theory and applications. They may not be well known among the largely North American audience, but a full presentation here would be prohibitive.

\section{COST FUNCTIONS IN RETAILING}

Recently, some studies have been conducted concerning cost functions on the level of individual establishments (=shops) in retailing. These cost functions have not been derived from some theoretically plausible and analytically flexible retail production function. See Caves, Christensen and Swanson (1981) for an example of methodology and empirical evidence using U.S. Railroad data. The application of duality theory to neoclassical economic problems shows that there is a one to one relation between production functions and cost functions - see Diewert (1974), for instance. In the context of retailing there are problems concerning the plausibility of neoclassical theory. The application of the concept of a traditional function (or its implication based on duality considerations) has serious drawbacks. First, the absence of a physical product. According to Nooteboom (1982, p. 163) "retailing does not produce a physical product that can be stocked, but offers a service capacity to be used at the discretion of customers"'. Hence, retailers are faced with the problem of the efficient use of existing capacity rather than with operational efficiency in the sense of choosing from different combinations of input factors. Second, there is a serious lack of homogeneity concerning the service capacity because it may have various dimensions such as assortment composition, accessibility, waiting time, price level, atmosphere, attractiveness, mode of service, reliability, etc. which may occur in various combinations. Moreover, it is questionable whether simple behavioral rules (profit maximization, cost minimization) apply in retailing with its many small independents who are unable or unwilling to recognize or to follow these rules. Lastly, imperfectness of competition due to partial spatial monopolies renders the use of the neoclassical concept implausible (Nooteboom, 1980, p. 19). Neoclassical exercises using retail data do not always lead to satisfactory results (White, 1976; Bode and Koerts, 1985; and Nooteboom, 1980, Appen$\operatorname{dix}$ A).

The cost functions mentioned above have been derived based upon the specific nature of retail operations. Nooteboom (1982) provides a theoretical justification of these cost functions using queuing theory and previous work (Nooteboom, 1980) for a critical discussion of the applicability of general theories of the firm (neoclassical, behavioral and managerial theories) for developing the retail cost function. These cost functions have the form of linear non-homogeneous relationships existing per shop type between volume of labor or total floorspace on the one hand and value of yearly sales on the other. Furthermore, it is assumed that these relationships can be studied separately. In the case of volume of labor, this relationship reads: 


$$
\mathrm{L}_{\mathrm{i}}=\alpha_{0}+\alpha_{1} \mathrm{Q}_{\mathrm{i}} \text { with } \alpha_{0}>0 \text { and } \alpha_{1}>0,
$$

where $\mathrm{L}_{\mathrm{i}}$ : volume of labor in shop $\mathrm{i}$;

$\mathrm{Q}_{\mathrm{i}}$ : value of yearly sales in shop $\mathrm{i}$;

$\alpha_{0}$ : threshold coefficient, whose value depends on the properties of the shop type. Or in other words, the value of $\alpha_{0}$ is not necessarily equal across shop types;

$\alpha_{1}$ : slope coefficient, whose value depends on the properties of the shop type.

The value of the threshold coefficient depends on the minimum amount of labor which must be at hand during all opening hours. This capacity is independent of the use made of it and equals the sum of opening times of all separately staffed departments in the shop. The number of separately staffed departments equals one in most small counter service shops and this one "department" is staffed by the owner/manager or his (part-time) representative (usually a family member). In such cases threshold labor equals annual opening time. Larger retail establishments often have more than one separately staffed department, e.g., cashier in a self-service establishment or a butcher in the butchery department of a supermarket. In these cases threshold labor equals a multiple of annual opening time — c.f. Nooteboom (1982).

The slope coefficient may also be called scale adjusted labor intensity because rewriting equation (1) gives

$$
\mathrm{L}_{\mathrm{i}} / \mathrm{Q}_{\mathrm{i}}=\alpha_{1}+\alpha_{0} / \mathrm{Q}_{\mathrm{i}},
$$

where $L_{i} / Q_{i}$ represents labor intensity (the inverse of labor productivity), $\alpha_{1}$ the scale $(=$ sales $)$ independent share and $\alpha_{0} / \mathrm{Q}_{\mathrm{i}}$ the scale dependent share of this intensity.

Labor intensity decreases with increasing scale $\left[\mathrm{d}\left(\mathrm{L}_{\mathrm{i}} / \mathrm{Q}_{\mathrm{i}}\right) / \mathrm{dQ}_{\mathrm{i}}<0\right]$, but at a decreasing pace $\left[\mathrm{d}^{2}\left(\mathrm{~L}_{\mathrm{i}} / \mathrm{Q}_{\mathrm{i}}\right) / \mathrm{dQ} \mathrm{Q}_{\mathrm{i}}^{2}>0\right]$, if $\alpha_{1}>0$ and $\alpha_{0}>0$. In other words, the retail sector can be characterized by scale economies particularly at low output levels.

Differences in scale adjusted labor intensity per shop for different shop types have been studied in detail (Nooteboom, 1980; Thurik, 1984a, 1984b and 1986). Important explanatory variables appear to be wage rate, assortment composition, share of self-service, level of own production, mode of supply to the shop, etc. Moreover, productivity growth has been studied using relationship (1) above (Nooteboom, 1983a; Thurik and Kleijweg, 1985).

Finally, the relationship is a tool to investigate specific topics such as the influence of trading hours in Nooteboom (1983b), the influence of the use of part-time labor in Thurik and Van der Wijst (1984), the influence of chain size in Thurik and Vollebregt (1985).

Concerning floorspace, the relationship reads:

$$
\mathrm{F}_{\mathrm{i}}=\beta_{0}+\beta_{1} \mathrm{Q}_{\mathrm{i}} \text { with } \beta_{0}>0 \text { and } \beta_{1}>0,
$$

where $\mathrm{F}_{\mathrm{i}}$ : total available floorspace of shop $\mathrm{i}$; 
$\beta_{0}$ : threshold coefficient, whose value depends on the properties of the shop type;

$\beta_{1}$ : scale adjusted floorspace intensity, whose value depends on the properties of the shop type.

Drawbacks of the use of floorspace equation (3) are that the theoretical justification is less solid than in the case of the labor equation, and that in empirical studies the statistical explanation is considerably less than in the case of the labor equation. ${ }^{1}$ Estimates of the threshold coefficient in the floorspace equation are often close to 50 square meters, which seems to be a reasonable space requirement for one separately staffed department (Nooteboom, 1980).

The assumption that labor and the floorspace relationships can be studied separately is based on the consideration that any substantial substitution of capital (floorspace) for labor alters the service level or the product, so that the classification (= shop type) of a particular shop changes. Substitution could be a useful concept when studying differences between shop types, rather than those within shop types. However, it is questionable whether the ratio of capital to labor is regulated by their relative prices only. It also can be regulated by the demand for a certain service level or product. Finally, opportunities for substitution are frustrated by the short-term rigidity of floorspace (Nooteboom, 1980).

Application of duality theory to derive a production function from the cost functions presented above is not meaningful in view of the drawbacks of the use of neoclassical theory in the area of retailing.

\section{GENERALIZED COST FUNCTIONS}

The present study is concerned with the relationship between average volume of labor or average total floorspace on the one hand and average value of yearly sales per establishment type on the other. The establishment types do not all refer to the retail trade. However, most do and the remaining types are involved in the catering business, handicrafts or wholesaling. Refer to Table 1 for a list of establishment types.

Equation (1) is a relationship between labor and sales on the level of individual establishments. Simple aggregation leads to a relationship between average labor per establishment in an establishment type $\mathrm{j}, \mathrm{L}_{\mathrm{j}}$ and average sales, $\mathrm{Q}_{\mathrm{j}}: \mathrm{L}_{\mathrm{j}}=\alpha_{0}+$ $\alpha_{1} Q_{j}$. Application of the latter relationship in empirical studies would imply the following assumptions:

a) equal threshold labor, $\alpha_{0}$, across establishment types

b) equal labor intensity, $\alpha_{1}$, across establishment types

c) no opportunity for replacement of capital, proxied by floorspace, for labor.

Generally, it is not realistic to assume equal threshold labor across establishment types, since threshold labor depends upon opening time and number of

1. A different concept of the relation between sales and floorspace is therefore proposed by Thurik (1984a). Kooiman, Van Dijk and Thurik (1985) incorporate this concept in a disequilibrium model for retail services. 
independently staffed departments. It will be shown, however, that the assumption of uniform threshold labor is not unrealistic in the present case. The assumption of equal labor intensity will be relaxed, in the sense that its value will be allowed to depend upon various establishment type properties. These dependencies will be tested in the context of four hypotheses: HT3, HT6, HT8 and HT10. In terms of the mathematical relationship this relaxation means that $\alpha_{1}$ will be replaced by $\alpha_{1 \mathrm{j}}$. At the end of this section a test will be proposed on the replacement opportunity.

Maintaining the equivalence between the labor and floorspace approach, two cost functions are proposed at the aggregated, averaged level:

$$
\mathrm{L}_{\mathrm{j}}=\alpha_{0}+\alpha_{1 \mathrm{j}} \mathrm{Q}_{\mathrm{j}}
$$

and

$$
F_{j}=\beta_{0}+\beta_{1 j} Q_{j},
$$

where $L_{j}$ : average volume of labor per establishment in establishment type $j$;

$Q_{j}$ : average value of yearly sales in establishment type $j$;

$\mathrm{F}_{\mathrm{j}}$ : average total floorspace in establishment type $\mathrm{j}$;

$\alpha_{0}$ : uniform threshold labor;

$\beta_{0}$ : uniform threshold floorspace;

$\alpha_{1 \mathrm{j}}$ : scale adjusted labor intensity, dependent upon establishment type properties;

$\beta_{1 \mathrm{j}}$ : scale adjusted floorspace intensity, dependent upon establishment type properties.

The assumption of uniform thresholds is made for convenience. It is also not unrealistic because most establishment types are small and may be assumed to have only one separately staffed department. In order to select a priori values for $\alpha_{0}$ and $\beta_{0}$, assumptions must be made about the average number of separately staffed departments and the ratio between opening time and working time per employee. It seems reasonable to assume that approximately two thirds of the establishment types have one separately staffed department and one third has two; the average number of separately staffed departments then becomes $11 / 3$. Yearly opening time exceeds yearly working time per employee (called full-time equivalent). The ratio of yearly opening time to yearly working time per employee is assumed to be three to two. ${ }^{2}$ Threshold labor then equals two $\left(=\frac{4}{3} \times \frac{3}{2}\right)$ full-time equivalents, ${ }^{3}$ and threshold floorspace then equals $65\left(\approx \frac{4}{3} \times 50\right) \mathrm{m}^{2}$.

2. These assumptions of the average number of departments and the ratio between opening time and working time per employee are tentative. They are not essential. It is important that positive values for the estimates of $\alpha_{0}$ and $\beta_{0}$ are found, so that the average number of departments can be deduced from the estimate of $\beta_{0}$ (assuming that one department has a threshold of 50 square metres). The ratio between opening time and working time per employee can be deduced from the estimate of $\alpha_{0}$ (assuming that at least one employee be present per separately staffed department). 3. A threshold of two full-time equivalents also was found for the French retail trade in 1978 (partitioned into 34 shop types involving some 400,000 establishments) - see Thurik and Vollebregt (1984). Thurik and Van Schaik (1984) reported thresholds of one and a half full-time equivalent and $43 \mathrm{~m}^{2}$ for some 1,800 small Dutch retail establishments partitioned into 85 shop types in 1981. 
The following testable hypotheses can now be formulated:

HT1: average threshold labor equals approximately two full-time equivalents $\left(\alpha_{0}=2\right)$;

HT2: average threshold floorspace equals approximately $65 \mathrm{~m}^{2}\left(\beta_{0}=65\right)$.

Clearly, there are large differences in the scale adjusted labor intensities $\left(\alpha_{1 j}\right)$ and floorspace intensities $\left(\beta_{1 \mathrm{l}}\right)$ between shop types. They find their cause in the heterogeneities across the establishment types. In the succeeding part of this section we shall formulate further hypotheses to be tested as regards the explanation of these differences. We first introduce the variable "percentage selling space" (= selling space divided by total floorspace). When the share of self-service increases, percentage selling space increases. When the degree of handicraft increases, percentage selling space decreases, provided the form of handicraft in question is not performed on the selling space. Hairdressers are left out of our analyses, because here the handicraft is performed on the selling price. It is assumed that labor intensity decreases and that floorspace intensity increases when the share of self-service increases and/or the degree of handicraft decreases.

HT3: scale adjusted labor intensity decreases when the average percentage selling space per establishment type increases;

HT4: scale adjusted floorspace intensity increases when the average percentage selling space per establishment type increases.

As far as the influence of rental paid is concerned, it is assumed that the average rental paid per square metre is an indicator of the attractiveness of the location. Another assumption is that the motivation to use available floorspace efficiently is induced by the height of average rental paid per square metre (Nooteboom, 1980; Thurik, 1984a).

HT5: scale adjusted floorspace intensity decreases when the average rental paid per square metre per establishment type increases.

Unfortunately, there is no information about the average price of labor, which means that the influence of the wage rate on labor intensity cannot be tested. Labor and floorspace intensity will certainly be influenced by the type of product sold by the establishment type. An a priori assumption about the sign of this influence is not always available, so that strictly speaking no well-defined hypotheses are being tested:

HT6: scale adjusted labor intensity depends on whether an establishment type sells food or non-food;

HT7: scale adjusted floorspace intensity depends on whether an establishment type sells food or non-food;

HT8: scale adjusted labor intensity is higher for establishment types involved in the catering business than for other establishment types (primarily retailing);

HT9: scale adjusted floorspace intensity depends on whether or not establishment types are involved in the catering business. 
Next, the role of the location of establishments is incorporated. The fact that establishment subgroups are made according to type of location enables this extension of the study. One should bear in mind that the attractiveness of the location is already indicated by the average rental paid per square metre. Two types of location are distinguished:

- type A: locations in shopping centres or on central shopping streets;

- type B: suburban or isolated locations.

It is assumed that establishments with a type B location have lower labor and floorspace intensities than establishments with a type A location, because the former establishments:

1. have less competitors, so that a lower service level can be offered, charging higher prices;

2. are confronted with less fluctuation in the distribution of the number of customers' arrivals. (Establishments with a type A location have to deal with a concentration of arrivals around noon and towards closing time, during shopping evenings and on Saturdays. This concentration will also occur for establishments with a type B location, but less pronounced, owing to the proximity of residential areas);

3. have to be run efficiently, otherwise they cannot survive outside central areas.

It is assumed that labor and floorspace intensities increase if the service level increases and when fluctuation in the distribution of customers' arrivals increases.

HT10: scale adjusted labor intensity is higher for establishments located in a shopping centre or a central shopping-street than for those having a suburban or isolated location;

HT11: scale adjusted labor floorspace intensity is higher for establishments located in a shopping centre or a central shopping-street than for those having a suburban or isolated location.

Finally, it is necessary to address whether or not it is justified to study the use of labor and floorspace separately. This question was raised in the last paragraph of the section on cost functions in retailing, where it was proposed that there are opportunities for replacement of capital (floorspace) for labor within shop types. ${ }^{4}$ No opportunities for replacement of capital for labor are assumed to occur between shop types (or between establishment types if the present analysis is not limited to the retail trade) using cross-section averages, because the service level and the product mix depend on the relative use of capital and labor.

HT12: no opportunities for replacement of capital for labor occur between establishment types.

4. The word replacement is used rather than substitution, because the latter is too much associated with price effects in a neoclassical environment. 
This hypothesis is tested using the vectors of residual values of the estimated generalized cost functions (4) and (5). HT12 must be rejected if the correlation coefficient between these vectors is negative, meaning that high labor intensity coincides with low floorspace intensity.

$$
\mathrm{L}_{\mathrm{j}}=\alpha_{0}+\alpha_{1 \mathrm{j}}^{\prime} \mathrm{Q}_{\mathrm{j}} \mathrm{RE} \hat{\mathrm{S}}_{\mathrm{j}}^{\alpha_{3}},
$$

where RÊS $S_{j}$ is computed in

$$
F_{j}=\hat{\beta}_{0}+\hat{\beta}_{1 j} Q_{j} R \hat{E} S_{j},
$$

where $\hat{\beta}_{0}$ and $\hat{\beta}_{1 \mathrm{j}}$ are the estimates of $\beta_{0}$ and $\beta_{1 \mathrm{j}}$ computed with (5).

HT12 must be rejected if $\alpha_{3}<0$. This rather technical procedure can easily be explained in words. If $\alpha_{3}<0$, there appears to be a relation between labor and floorspace in the sense that a relative overcapacity of labor results in a relative undercapacity of floorspace and vice versa. The hypothesis of a replacement opportunity between the two cannot be rejected if this effect is systematic across establishment types. The rationale of the multiplicative specification of the residual value, RES, will be given in the next section.

\section{RESULTS}

Equations (4) and (5) have to be expanded to permit simultaneous statistical tests for HT3 through HT12. A description of the data used, as well as a detailed report on the findings from a statistical point of view, will be provided in this section. The next section concentrates on the findings from an economics point of view.

The following specification for $\alpha_{1 j}$, the scale adjusted labor intensity, in equation (4) is proposed on basis of HT3, HT6, HT8, HT10 and HT12:

$$
\alpha_{1 \mathrm{j}}=\alpha_{1}\left(\frac{\mathrm{PSS}_{\mathrm{j}}}{\mathrm{PSS}}\right)^{\alpha_{2}} \mathrm{RES}_{\mathrm{j}}^{\alpha_{3}} \exp \left(\alpha_{4} \mathrm{DFO}_{\mathrm{j}}+\alpha_{5} \mathrm{DCB}_{\mathrm{j}}+\alpha_{6} \mathrm{DSC}_{\mathrm{j}}\right) \text {, }
$$

where PSS $_{\mathrm{j}}$ : average percentage selling space in establishment type j. PSS $\mathrm{P}_{\mathrm{j}} \triangleq$ $\mathrm{S}_{\mathrm{j}} / \mathrm{F}_{\mathrm{j}}$, where $\mathrm{S}_{\mathrm{j}}$ is average selling space, and $\mathrm{F}_{\mathrm{j}}$ is average total floorspace in establishment type $\mathrm{j}$;

PSSS: sample average percentage selling space.

$\overline{P S S} \triangleq\left(\sum_{j=1}^{J} \operatorname{PSS}_{\mathrm{j}}\right) / J$, where $\mathrm{J}$ is total number of establishment subgroups. For convenience these subgroups are also referred to as establishment types;

$R \hat{E} S_{j}$ : residues of the estimated floorspace cost function. See equation (7);

$\mathrm{DFO}_{\mathrm{j}}$ : dummy variable taking value one if the establishment type $\mathrm{j}$ is involved in selling food and value zero otherwise;

DCB $_{j}$ : dummy variable taking value one if the establishment type $\mathrm{j}$ is involved in the catering business and value zero otherwise; 
DSC $_{\mathrm{j}}$ : dummy variable taking value one if the establishment type $\mathrm{j}$ consists of establishments having a central location (shopping centre or central shopping-street) and value zero otherwise.

The following specification for $\beta_{1 \mathrm{j}}$, the scale adjusted floorspace intensity, in equation (5) is proposed on basis of HT4, HT5, HT7, HT9 and HT11:

$$
\beta_{1 j}=\beta_{1}\left(\frac{\mathrm{PSS}_{\mathrm{j}}}{\overline{\mathrm{PSS}}}\right)^{\beta_{2}}\left(\frac{\mathrm{RP}}{\overline{\bar{R}} \mathrm{P}}\right)^{\beta_{3}} \exp \left(\beta_{4} \mathrm{DFO}_{\mathrm{j}}+\beta_{5} \mathrm{DCB}_{\mathrm{j}}+\beta_{6} \mathrm{DSC}_{\mathrm{j}}\right),
$$

where $\underline{R P}_{\mathrm{j}}$ : average rental paid per square metre in establishment type $\mathrm{j}$;

$\bar{R} P$ : sample average rental paid per square metre.

A multiplicative specification is chosen, because such a specification accounts for interaction between variables in their influence on $\alpha_{1 \mathrm{j}}$ and $\beta_{1 \mathrm{j}}$.

The coefficients in (8) and (9) have the following interpretation:

$\alpha_{1}$ :scale adjusted labor intensity for establishment types with PSS $=P \overline{S S}, R_{\hat{E} S}=1$ and $\mathrm{DFO}_{\mathrm{j}}=\mathrm{DCB}_{\mathrm{j}}=\mathrm{DSC}_{\mathrm{j}}=0$ (i.e. non-food retail establishments, which are not centrally located);

$\alpha_{2}$ :elasticity of $\alpha_{1 j}$ with respect to relative percentage selling space, $\mathrm{PSS}_{\mathrm{j}} / \mathrm{PSS}$;

$\alpha_{3}$ :elasticity of $\alpha_{1 j}$ with respect to the residue of the floorspace cost function, RES;

$\alpha_{4}, \alpha_{5}, \alpha_{6}$ :influences of establishment type and location;

$\beta_{1}$ :scale adjusted floorspace intensity for establishment types with $\mathrm{PSS}_{\mathrm{j}}=\mathrm{PSS}, \mathrm{RP}_{\mathrm{j}}=\overline{\mathrm{RP}}$ and $\mathrm{DFO}_{\mathrm{j}}=\mathrm{DCB}_{\mathrm{j}}=\mathrm{DSC}_{\mathrm{j}}$ $=0$;

$\beta_{2}$ :elasticity of $\beta_{1 j}$ with respect to relative percentage selling space, PSS $_{\mathrm{j}} / \mathrm{PSS}$;

$\beta_{3}$ :elasticity of $\beta_{1 j}$ with respect to relative rental paid, $\mathrm{RP}_{\mathrm{j}} / \overline{\mathrm{R}} \mathrm{P}$;

$\beta_{4}, \beta_{5}, \beta_{6}$ :influences of establishment type and location.

If equations (8) and (9) are substituted into (4) and (5), respectively, and disturbance terms are added. Then:

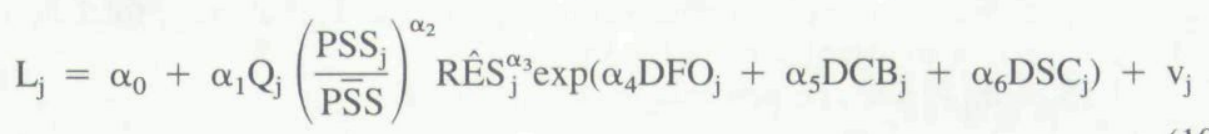

and

$$
F_{j}=\beta_{0}+\beta_{1} Q_{j}\left(\frac{P S S_{j}}{P \overline{S S}}\right)^{\beta_{2}}\left(\frac{R P_{j}}{\bar{R} P}\right)^{\beta_{3}} \exp \left(\beta_{4} D P_{j}+\beta_{5} D_{C B}+\beta_{6} D C_{j}\right)+w_{j}
$$

where $L_{j}$ : average volume of labor per establishment in establishment type $j$ (in number of persons engaged); 
$\mathrm{Q}_{\mathrm{j}}$ : $\quad$ average value of yearly sales in establishment type $\mathrm{j}$ (in $10^{4}$ South African Rands);

$F_{j}: \quad$ average floorspace in establishment type $\mathrm{j}$ (in square metres);

$\mathrm{v}_{\mathrm{j}}, \mathrm{w}_{\mathrm{j}}$ : disturbance terms: independently distributed stochastic variables with zero means and constant variances.

Equations (10) and (11) are called generalized labor and floorspace cost functions. They are estimated, using data of 23 establishment types distributed among 96 subgroups $(\mathrm{J}=96)$ according to their location, involving a total of 1,128 establishments. Data can be found in "Sales, Rental and Establishment Size and their Interrelationships in the Municipal Area of Pretoria 1979/1980", Report No. A8 (Bureau of Financial Analysis, University of Pretoria), 1981. Several groups per establishment type are distinguished according to type of location. All establishments are located in Pretoria, Republic of South Africa (R.S.A.). A further description of the data used is given in Table 1. The data are collected in 1979 and 1980.

Equations (10) and (11) cannot be linearized due to the occurrence of both additive or multiplicative parts. The multiplicative specification of (8) and (9) is essential for a proper estimation of the threshold values, $\alpha_{0}$ and $\beta_{0}$, and for a useful comparison with other results where multiplicative specifications have been used. See conclusions from Table 2. A non-linear least square fit using Marquardt's (1963) algorithm is applied to produce the estimation results given in Table 2. Algorithms like Marquardt's usually converge only to local minima. Therefore various (largely differing) initial values are tried: they consistently produce the same optimal value of the coefficient vector.

Presumably, consultants' and small business managers' computer program libraries do not contain non-linear least squares methods. The use of a non-linear method is avoidable if an a priori value of the threshold value is available, because then equations such as (10) and (11) are easily linearized. Bringing $\alpha_{0}$ and $\mathrm{Q}_{\mathrm{j}}$ to the left-hand side of (10), deleting the disturbance term, $\mathrm{v}_{\mathrm{j}}$, taking logarithms on both sides and adding a "new" disturbance term $z_{j}$ gives:

$$
\begin{gathered}
\log \left(\frac{\mathrm{L}_{\mathrm{j}}-\alpha_{0}}{\mathrm{Q}_{\mathrm{j}}}\right)=\log \alpha_{1}+\alpha_{2} \log \left(\frac{\mathrm{PSS}_{\mathrm{j}}}{\mathrm{PS} S}+\alpha_{3} \log \mathrm{RE}_{\mathrm{j}}+\right. \\
\alpha_{4} \mathrm{DFO}_{\mathrm{j}}+\alpha_{5} \mathrm{DCB}_{\mathrm{j}}+\alpha_{6} \mathrm{DSC}_{\mathrm{j}}+\mathrm{z}_{\mathrm{j}} .
\end{gathered}
$$

Equation (12) can easily be estimated using a linear least squares fit provided an a priori estimate of $\alpha_{0}$ is available. If this is not the case a preliminary estimation of the following type, deleting all variables on the right-hand side of (12), may be useful [cf. equation (4)]:

$$
\mathrm{L}_{\mathrm{j}}=\alpha_{0}+\alpha_{1} \mathrm{~W}_{\mathrm{j}}+\mathrm{x}_{\mathrm{j}}
$$

where $\mathrm{x}_{\mathrm{j}}$ : disturbance term.

This two-step procedure, (estimation of $\alpha_{0}$ in (13) and estimation of the remaining coefficients in (12), is proposed by Nooteboom (1980) in his early work 


\section{Table 2}

\section{Estimates of the Coefficients}

Labor Cost Relation

\begin{tabular}{|c|c|c|c|c|c|}
\hline Threshold & HT1: $\alpha_{0}=2$ & $\hat{\alpha}_{0}=$ & $\begin{array}{l}2.77 \\
(.34)\end{array}$ & HT2: $\beta_{0}=65$ & $\hat{\beta}_{0}=\begin{array}{c}70.53 \\
(12.31)\end{array}$ \\
\hline $\begin{array}{l}\text { "Average" scale adjusted } \\
\text { labor/floorspace intensity }\end{array}$ & $\alpha_{1}>0$ & $\hat{\alpha}_{1}=$ & $\begin{array}{l}.13 \\
(.02)\end{array}$ & $\beta_{1}>0$ & $\begin{array}{ll}\hat{\beta}_{1}= & 4.01 \\
(.56)\end{array}$ \\
\hline Percentage selling space & HT3: $\alpha_{2}<0$ & $\hat{\alpha}_{2}=$ & $\begin{array}{l}-.05 \\
(.11)^{*}\end{array}$ & HT $4: \beta_{2}>0$ & $\begin{array}{ll}\hat{\beta}_{2}= & 1.27 \\
(.21)\end{array}$ \\
\hline $\begin{array}{l}\text { Replacement opportunity/ } \\
\text { rental paid }\end{array}$ & HT12: $\alpha_{3}>0$ & $\hat{\alpha}_{3}=$ & $\begin{array}{l}1.03 \\
(.15)\end{array}$ & HT5: $\beta_{3}<0$ & $\hat{\beta}_{3}=-1.14$ \\
\hline Foods & HT6: $\alpha_{4}$ ? & $\hat{\alpha}_{4}=$ & $\begin{array}{l}-.10 \\
(.12)^{*}\end{array}$ & HT7: $\beta_{4}$ ? & $\hat{\beta}_{4}=-.48$ \\
\hline Catering business & HT8: $\alpha_{5}>0$ & $\hat{\alpha}_{5}=$ & $\begin{array}{l}1.02 \\
(.09)\end{array}$ & HT9: $\beta_{5}$ ? & $\begin{array}{l}\hat{\beta}_{5}=-.04 \\
(.18)^{*}\end{array}$ \\
\hline Central location & HT10: $\alpha_{6}>0$ & $\hat{\alpha}_{6}=$ & $\begin{array}{l}.22 \\
(.10)\end{array}$ & HT11: $\beta>0$ & $\hat{\beta}_{6}=\quad .33$ \\
\hline Number of observations & & $\mathbf{J}=$ & 96 & & $\mathrm{~J}=96$ \\
\hline Goodness of fit & & $r^{2}=$ & .75 & & $r^{2}=.79$ \\
\hline
\end{tabular}

Note: No analytical expression is available for the standard error of the estimated coefficients. They are computed numerically within the algorithm. It is assumed that estimated coefficients are asymptotically normally distributed. Estimated standard errors $(\hat{\sigma})$ are printed beneath the estimated coefficients. Coefficient $\hat{\eta}$ is called significantly different from zero at a 5\% level of significance, if $|\hat{\eta}|>2 \hat{\sigma}(\hat{\eta})$. An asterisk $\left.{ }^{*}\right)$ is printed next to $\hat{\sigma}(\hat{\eta})$, if $|\hat{\eta}|<2 \hat{\sigma}(\hat{\eta})$, i.e. if $\hat{\eta}$ is not significantly different from zero. The square of the correlation coefficient between the vectors of the dependent variable and its estimation is taken as measure of goodness of fit.

and generally yields results comparable to those using (10).

It can be concluded from Table 2 that:

1. $\hat{\alpha}_{0}>0$, and is significant. Economies of scale with respect to the use of labor can be obtained. However, $\hat{\alpha}_{0}>2$ and significantly, which would imply the rejection of HT1. This overestimation of $\hat{\alpha}_{0}$ is probably caused by the fact that $\mathrm{L}_{\mathrm{i}}$ is measured in persons engaged and not in full-time equivalents. (Nooteboom, 1980, 1982; Thurik and Van der Wijst, 1984; and Thurik, 1986);

2. $\hat{\beta}_{0}>0$, and is significant. Economies of scale with respect to the use of floorspace can be obtained. In addition, $\hat{\beta}_{0}$ does not differ significantly from 65 square metres, so that HT2 is supported. (Nooteboom, 1980);

3. The scale adjusted labor intensity for non-food retail establishments which are not centrally located and with PSS $_{j}=P \bar{S} S$ and RES $_{j}=1$ is .13 persons engaged per $10^{4}$ South African Rands. The scale adjusted floorspace intensity for these establishments with $\mathrm{PSS}_{\mathrm{j}}=\mathrm{PS} S$ and $\mathrm{RP}_{\mathrm{j}}$ $=\overline{\mathrm{RP}}$ is four square metres per $10^{4}$ South African Rands;

4. $\hat{\alpha}_{2}<0$, but is not significant. The hypotheses (HT3) that scale adjusted labor intensity decreases when the average percentage selling space per 
establishment type increases, is not supported. $\beta_{2}>0$, and is significant. The hypothesis (HT4) that scale adjusted floorspace intensity increases when the average percentage selling space per establishment type increases, is supported. (Nooteboom, 1980);

5. $\hat{\alpha}_{3}>0$, and is significant. The hypothesis (HT12) that no opportunities for replacement of capital for labor occurs between establishment types, is supported. The significantly positive value of $\hat{\alpha}_{3}$ is probably caused by the omission of variables in both cost relations, which have influences by the same "sign" on both scale adjusted labor and floorspace intensity;

6. $\beta_{3}<0$, and is significant. The hypothesis (HT5) that scale adjusted floorspace intensity decreases when the average rental paid per square metre per establishment type increases, is supported. (Nooteboom, 1980; and Thurik, 1984a);

7. $\hat{\alpha}_{4}<0$, but is not significant and $\hat{\beta}_{4}<0$, and is significant. Both scale adjusted labor and floorspace intensity are lower for food establishments than for non-food establishments (cf. HT6 and HT7). These results however, are not significant for labor intensity. (Thurik and Vollebregt, 1984; and Thurik and Van Schaik, 1984);

8. $\hat{\alpha}_{5}>0$, and is significant. The hypothesis (HT8) that scale adjusted labor intensity is higher for establishment types involved in the catering business than for other establishment types, is supported. No influence is found as regards scale adjusted floorspace intensity (cf. HT9): $\hat{\beta}_{5}$ does not differ significantly from zero;

9. $\hat{\alpha}_{6}>0$, and $\hat{\beta}_{6}>0$, and are significant. The hypotheses, HT10 and HT11, that both scale adjusted labor and floorspace intensity are higher for establishments located in a shopping centre or a central shopping street than for those having a suburban or isolated location, are supported;

10. the statistical explanation of both relations is satisfactory in view of the fact that largely differing trade groups are used. The statistical explanation of the labor cost relation drops if $R \hat{E} S_{j}$ is deleted $\left(r^{2}=.60\right)$. It is expected to increase, when full-time equivalents are considered instead of total employees and when the price of labor (wage rate) is available.

\section{CONCLUSIONS}

Generalized labor and floorspace cost functions for small business trade groups were derived above in equations (10) and (11). They are derived on basis of equations (4) and (5) and hypotheses HT1 through HT12. They are estimated using data from establishments located in the Pretoria area. The estimation results tell us that:

1. the values of the threshold coefficients in both cost functions are in accordance with what might be expected. They are approximately 2.8 full-time equivalent for the labor cost function (cf. H1) and approximately $70 \mathrm{~m}^{2}$ for the floorspace cost function (cf. H2). The concept of a threshold (with respect to both labor and floorspace) plays an important role in the theoretical derivation of our generalized cost functions. The positive values of 
the threshold coefficients imply that economies of scale can be obtained with respect to the use of both labor and floorspace;

2. differences in labor and floorspace intensities (the inverses of labor and floorspace productivities) depend primarily on the average value of annual sales per establishment;

3. moreover, the question whether establishments are involved in the catering business or not and whether they have a central location or not, is of significant influence on the scale adjusted labor intensity. The scale adjusted labor intensity is defined as labor minus threshold labor divided by annual sales-see equation (2). Establishments involved in the catering business have a scale adjusted labor intensity which is approximately 170 percent higher than those involved in retailing and handicrafts (cf. HT8). Establishments with a central location have a labor intensity which is approximately 25 per cent higher than those with no central location (cf. HT10);

4. scale adjusted floorspace intensity is significantly influenced by percentage selling space, rental paid per square metre, whether food is sold or not and whether establishments have a central location or not. The elasticity of scale adjusted floorspace intensity with respect to percentage selling space is approximately 1.27 (cf. HT4). The elasticity of scale adjusted floorspace intensity with respect to rental paid per square metre is approximately -1.14 (cf. HT5). Establishments selling food have a scale adjusted floorspace intensity which is approximately 62 per cent lower than those selling non-food (cf. HT7). Establishments with a central location have a scale adjusted floorspace intensity which is approximately 39 per cent higher than those with no central location (cf. HT11);

5. statistical explanation is satisfactory in view of the largely differing trade groups considered;

6. it appears that both cost functions may indeed be studied separately (cf. HT12).

Points of interest for further scientific research are:

- investigation of the role of the wage rate in the labor costs relation;

- explanation of the positive value of the correlation coefficient of the vectors of residuals of the estimated labor cost relation and floorspace cost relation;

- extension of the analysis in order to explain not only labor and rental costs, but also remaining costs, so that total costs are explained;

- development of labor and floorspace intensity in time. Estimations in this study refer to $1979 / 1980$. Development in time can be studied if similar estimations can be made for preceding or succeeding years. Especially differences in the for scale etc. adjusted labor and floorspace intensities, $\alpha_{1}$ and $\beta_{1}$, are open for interpretation.

In the area of consulting, the present study is meaningful only for the Pretoria area. Consulting assistance elsewhere should be preceded by a similar analysis using data relating to the area in question. A productivity business support system can be developed to provide standards depending upon the specific char- 
acteristics of an establishment (group). The methodology in the present paper concentrates on the influence of size and location. However, the influence of type of product, type of labor used or type of organization can easily be taken into account as well. Analyses using French and Dutch data show results which are in accordance with those presented here. From this one may conclude that the methodology presented is certainly not restricted to the South African case, although application to other areas may produce different coefficient values due to a differing cultural, organizational, demographic settings, etc. For the time being the methodology should be restricted to service businesses (retailing, wholesaling, catering business, etc.). For applications in manufacturing, a reconsideration of HT12 (no opportunities for replacement of capital for labor to occur between establishment types) is obvious.

\section{REFERENCES}

Bode, B. and Koerts, J. (1985). The technology of retailing: A further analysis for furnishing firms: Report 8548/A, Econometric Institute, Erasmus University Rotterdam.

Caves, D. W., Christensen, L. R., and Swanson, J. A. (1981). Productivity growth, scale economies and capacity utilization in U.S. railroads, 1955-74; American Economic Review, 7I(5), 994-1002.

Diewert, W. E. (1974). Applications of Duality Theory: In M. D. Intriligator and D. A. Kendrick (eds), Frontiers of Quantitative Economics. Amsterdam: North Holland.

Marquardt, D. W. (1963). An algorithm for least squares estimation of non-linear parameters; Journal of Society for Industrial and Applied Mathematics, 11, 431-441.

Kooiman, P., van Dijk, H. K., and Thurik, A. R. (1985). Likelihood diagnostics and Bayesian analysis of a micro-economic disequilibrium model for retail services, Journal of Econometrics, $29,121-148$.

Nooteboom, B. (1980). Retailing: Applied analysis in the theory of the firm. Uithoorn, Netherlands: J. C. Gieben.

Nooteboom, B. (1982). A new theory of retailing costs; European Economic Review, 17, 163-186.

Nooteboom, B. (1983a). Productivity growth in the grocery trade, Applied Economics, 15, 649-664.

Nooteboom, B. (1983b). Trading hours and economy of scale in retailing, European Small Business Journal, 1(2), 57-62.

Thurik, A. R. (1984a). Quantitative analysis of retail productivity. Meinema: Delft, Netherlands.

Thurik, A. R. (1984b). Labour productivity, economies of scale and opening time in large retail establishments, Service Industries Journal, 4, 19-29.

Thurik, A. R. (1986). Transaction per customer in supermarkets, International Journal of Retailing, (forthcoming).

Thurik, A. R. and Kleijweg, A. J. M. (1985). Procyclical retail labor productivity, Bulletin of Economic Research, 38(2), 169-175.

Thurik, A. R. and van Schaik, H. A. C. (1984). Gegeneraliseerde kostenrelaties in de detailhandel', Maandblad voor Accountancy en Bedrijfshuishoudkunde, 58, 203-217. 
Thurik, A. R. and Vollebregt, J. A. C. (1984). A generalized labor cost relation for French retailing, Annales de l'INSEE, 53, 93-106.

Thurik, A. R. and Vollebregt, J. A. C. (1985). Degree of affiliation and retail labor productivity in France, the Netherlands and the U.K., International Small Business Journal, 5(3), 65-71.

Thurik, A. R. and van der Wijst, D. (1984). Part-time labor in retailing, Journal of Retailing, $60(3), 62-80$.

White, L. J. (1976). The technology of retailing: Some results for department stores. In S. M. Goldfeld and R. E. Quandt, (eds.), Studies in Nonlinear Estimation. Cambridge: Ballinger.

A. Roy Thurik is head of the Department of Fundamental Research, Research Institute for Small and Medium-Sized Business, The Netherlands.

This paper is a revised version of Research Paper 8506 (Productivity in Small Business in South Africa) of the Research Institute for Small and Medium-Sized Business. The author wishes to thank the reviewers for their very useful suggestions. 
Copyright of American Journal of Small Business is the property of Entrepreneurship Theory \& Practice and its content may not be copied or emailed to multiple sites or posted to a listserv without the copyright holder's express written permission. However, users may print, download, or email articles for individual use. 